\title{
DERECHO ADMINISTRATIVO Y TECNOLOGÍA: EL TELETRABAJO EN LA FUNCIÓN PÚBLICA EN EL URUGUAY ${ }^{1}$
}

\author{
ADMINISTRATIVE LAW AND TECHNOLOGY: \\ TELEWORKING IN THE PUBLIC SERVICE IN URUGUAY
}

\section{DIREITO ADMINISTRATIVO E TECNOLOGIA: O TELETRABALHO NA FUNÇÃO PÚBLICA NO URUGUAI}

\author{
MARÍA JOSEFINA LORENZO, \\ SILVANA NESSAR DE LENOBLE ${ }^{3}$ \\ Y GUSTAVO FISCHER ${ }^{4}$
}

RECIBIDO: $30 / 10 / 2020$

ACEPTADO: $18 / 11 / 2020$

\begin{abstract}
RESUMEN: El Grupo de Investigación y Estudio en Derecho Administrativo de la Universidad de Montevideo ya en 2009 abordó el estudio del fenómeno del "teletrabajo" en la Administración Pública, al reflexionar sobre el Decreto No. 420/007 de 7 de noviembre de 2007 y sus modernas formas de prestación de la función pública. La realidad de la pandemia de COVID-19, que ha puesto de relieve esta modalidad de trabajo, justifica retomar aquellas ideas y analizarlas en su desarrollo y bajo la nueva realidad, con el ánimo de aportar al estudio y discusión de esta forma de prestación de función pública. Así, en este trabajo se releva y actualiza el fenómeno del teletrabajo en la Administración Pública en el derecho comparado, específicamente en España, y en el Gobierno Federal de los Estados Unidos. Pasando luego al análisis de la normativa existente en el Derecho
\end{abstract}

1 Trabajo elaborado por el Grupo de Investigación y Estudio en Derecho Administrativo de la Universidad de Montevideo, coordinado por Silvana Nessar de Lenoble.

2 Abogada por la Universidad de la República. ORCID ID: https://orcid.org/0000-0002-4426-3318. jlorenzo61@hotmail.com

3 Doctor en Derecho y Ciencias Sociales por la Universidad de la República. Procuradora del Estado Adjunta en lo Contencioso Administrativo. Profesor Titular Derecho Administrativo I y II, Titular Taller Recursos y Acción Anulatoria en la Facultad de Derecho de la Universidad de Montevideo. Profesor Titular Programa Master Derecho de la Empresa y Derecho Administrativo Económico, Módulo Recursos Administrativos y Acción Anulatoria y Módulo Acción Reparatoria y Acción de Inconstitucionalidad. Coordinadora Grupo de Investigación y Estudio en Derecho Administrativo. ORCID ID: https:/ / orcid.org/0000-0003-0149-2898. mnessar@correo.um.edu.uy

4 Doctor en Derecho y Ciencias Sociales por la Universidad de la República. Miembro del Grupo de Investigación y Estudio en Derecho Administrativo de la Universidad de Montevideo. Profesor Titular de Contenciosos de Derecho Público en Programa Master en Derecho Administrativo Económico en la Universidad de Montevideo. ORCID ID: https: / / orcid. org/0000-0001-8981-2424. gfischer@fischer.com.uy 
Positivo de Uruguay, y el examen de los antecedentes normativos en el área de teletrabajo y tecnología. Para, finalmente, valorar virtudes, defectos y prospectiva del teletrabajo en la Función Pública.

PALABRAS CLAVE: Teletrabajo, Función Pública, Tecnología, Derecho Administrativo, Uruguay.

ABSTRACT: The Research and Study Group in Administrative Law of the University of Montevideo already in 2009 addressed the study of the phenomenon of "telework" in the Public Administration, reflecting on Decree No. 420/007 of November 7, 2007 and its modern forms of civil service provision. The reality of the COVID-19 pandemic, which has highlighted this type of work, justifies taking up those ideas and analyzing them in their development and under the new reality, with the aim of contributing to the study and discussion of this form of provision of public function. Thus, in this work the phenomenon of teleworking in the Public Administration in comparative law is surveyed and updated, specifically in Spain, and in the Federal Government of the United States. Moving on to the analysis of the existing regulations in the Positive Law of Uruguay, and the examination of the legal and regulatory background in the area of telework and technology. Finally, to assess the virtues, defects and prospects of telework in Civil Service.

KEY WORDS: Telework, Civil Service, Technology, Administrative Law, Uruguay.

RESUMO: O Grupo de Pesquisa e Estudo em Direito Administrativo da Universidade de Montevidéu já havia abordado, em 2009, o estudo do fenômeno do "teletrabalho" na Função Pública, refletindo sobre o Decreto n ${ }^{\circ} 420 / 007$ de 7 de novembro de 2007 e suas formas modernas de prestação de serviços públicos. A realidade da pandemia de COVID-19, que põe evidência esta modalidade de trabalho, justifica retomar aquelas ideias e analisá-las em seu desenvolvimento e sob a nova realidade, com o intuito de contribuir ao estudo e discussão desta forma de prestação de função pública. Assim, neste trabalho, se aborda e atualiza o fenômeno do teletrabalho na Administração Pública no direito comparado, especificamente na Espanha, e no Governo Federal dos Estados Unidos. Seguindo com a análise da normativa existente no Direito Positivo do Uruguai, e o exame dos antecedentes normativos na área de teletrabalho e tecnologia. Finalmente, valorizar virtudes, defeitos e prospectiva do teletrabalho na Função Pública.

PALAVRAS-CHAVE: Teletrabalho, Função Pública, Tecnologia, Direito Administrativo, Uruguai.

\section{SUMARIO}

1. Justificación del trabajo. 2. Teletrabajo en el Derecho Comparado: 2.1 A c tualización Normativa: Teletrabajo en España. 2.2 Actualidad del Teletrabajo en el Gobierno Federal de los Estados Unidos. 3. Derecho Positivo en Uruguay. 3.1. Antecedentes Normativos. Teletrabajo y Tecnología. 3.2 Intersección entre teletrabajo en la función pública y otras normas. Protección de Datos Personales. Ciberseguridad. 4. Reflexiones finales. Virtudes, defectos y prospectiva. 


\subsection{Justificación del trabajo.}

El Grupo de Investigación y Estudio en Derecho Administrativo, creado a instancia de nuestro muy querido y siempre recordado Prof. Dr. Mariano Brito, ya en el año 2009 tuvo la inquietud de abordar el fenómeno del "teletrabajo", oportunidad en que lo hizo con motivo de reflexionar a propósito del Decreto 420/007, de 7 de noviembre de 2007 y sus modernas formas de prestación de la función pública ${ }^{5}$.

En esta ocasión nos convoca una muy distinta y triste realidad para retomar aquellas ideas expuestas en nuestro primigenio trabajo, realidad aparejada por el COVID-19 que nos enfrentó a una pandemia que hizo que esa modalidad de trabajo se impusiera a lo largo y ancho de todo el mundo.

El Derecho Administrativo, que entre sus características destaca su movilidad, no puede estar ajeno a esta situación, sino que debe responder a las necesidades de la comunidad, creando derecho acorde a esa nueva realidad.

En efecto, todos los autores son contestes en resaltar esas características tan particulares del Derecho Administrativo en relación a su movilidad y constante evolución ${ }^{6}$.

En ese sentido Brito, de inmejorable manera señaló: “El Derecho es contenido y forma dispuesta y organizada para permanecer, pero también en respuesta al acaecimiento vital, cambiante, y siempre prospectiva. La elaboración del Derecho Administrativo reclama su atención sin pausa a lo óntico que el hombre radica-aquello que él es y en él se da..." 7 .

No menos acertada frente a esta nueva realidad es la reflexión de Mario E. Federico, citado por Brito, cuando señala: “...el Estado no puede dejar de concebirse como agente de realización del bien común público y para ello debe disponer de todos los recursos que, en el marco de las convicciones colectivas universales que impulsan los derechos Humanos, le permiten superar las situaciones excepcionales en el marco de la razonabilidad de sus intervenciones inexcusables..." ${ }^{8}$.

De manera que, sin hesitación alguna, al Derecho Administrativo se le reclama y debe por tanto cumplir con esa su propia razón de existir - equilibrio entre el Estado y el Individuo - erigiéndose en fuente normativa que atiende esas necesidades actuales de la persona humana ${ }^{9}$.

\footnotetext{
5 Grupo de Investigación y Estudio de la Facultad de Derecho de la Universidad de Montevideo, "Reflexiones a propósito del Decreto 420/007 y las formas modernas de prestación de la función pública", Revista de Derecho de la Universidad de Montevideo, Año VIII, 2009, No. 16.

6 Rotondo, Felipe, "Manual de Derecho Administrativo", 7ª edición, Ediciones del Foro, Año 2009, pág. 24 y ss.

7 Brito, Mariano, "Derecho Administrativo, Su Permanencia-Contemporaneidad-Prospectiva”, UM, Mvdeo, Año 2004, pág. 9 y ss.

8 Federico, Mario E. “Gobernabilidad democrática y Estado de Derecho frente a las emergencias económicas y sociales", citado por Brito, Mariano, op. cit., pág. 15.

9 Meilán Gil, José Luis, citado por Rotondo Felipe op. cit., pág. 24 y ss.
} 
Por ello la regulación de esta modalidad de trabajo - el "teletrabajo" - no tan nueva ahora como aventuramos en aquel ya indicado trabajo, es una tarea en la que debe pues embarcarse esta rama del Derecho.

En ese sentido, en esta nueva incursión en el tema el Grupo se abocó a reflexionar sobre esta modalidad de trabajo en el ejercicio de la función pública tanto en nuestro derecho positivo como en el derecho comparado.

Para finalmente concluir con una valoración de la realidad actual y prospectiva del teletrabajo en la función pública en Uruguay.

\section{Teletrabajo en el Derecho Comparado.}

\subsection{Actualización Normativa. Teletrabajo en España.}

Incursionando inicialmente en la normativa aprobada en forma reciente en España, es de destacar que el 22 de setiembre de 2020 se emitió el Real Decreto -ley No. 28/2020 de trabajo a distancia, de aplicación para la actividad privada, y - en lo que en relación a este trabajo importa - el 29 de setiembre de 2020, se aprobó el Real Decreto -ley No. 29/2020 que regula el teletrabajo para la actividad pública.

Esta última norma - el Real Decreto-ley 29/2020, de 29 de setiembre de 2020 - adopta medidas urgentes en materia de teletrabajo en las Administraciones Públicas y de recursos humanos en el Sistema Nacional de Salud para hacer frente a la crisis sanitaria ocasionada por la COVID-19.

En lo referente al teletrabajo en las Administraciones Públicas, la finalidad de la norma, es asegurar el normal funcionamiento de aquéllas, impulsando nuevas formas de organización y estructuración del trabajo de los empleados públicos para el mejor servicio a los intereses generales, mediante el uso de nuevas tecnologías de la información y el desarrollo de la administración digital.

Se expresa en la exposición de motivos del Real Decreto-ley que durante la crisis sanitaria por COVID-19, las tecnologías de la información y comunicación han constituido una herramienta clave para reducir el impacto de las medidas de contención y restricciones en el trabajo de los empleados públicos en el contexto de incertidumbre, al tiempo que sienta las bases de una forma de organización de la prestación de servicios flexible y adaptable a cualesquier circunstancia que se pueda dar en el futuro.

En dicha exposición de motivos, se citan como antecedentes normativos el Acuerdo Marco Europeo sobre teletrabajo, suscrito en julio de 2002 y revisado en 2009; la Orden APU/1981/2006, del 21 de junio por la que se promovió la implantación de programas piloto de teletrabajo en los departamentos ministeriales y organismos públicos, así como otras normas que refieren al impulso de una buena administración, en la calidad y la eficacia de los servicios públicos mediante el uso de nuevas tecnologías. 
Dichas normas refieren al fomento de la conciliación y la corresponsabilidad de la vida personal, familiar y laboral, y otras tratan del reconocimiento de derechos relacionados con el uso de dispositivos digitales en el ámbito laboral, como por ejemplo derechos digitales en la negociación colectiva, derecho a la intimidad y uso de dispositivos en el ámbito laboral y derecho a la desconexión digital.

Se expresa que la implantación del teletrabajo y su uso efectivo en las Administraciones Públicas no se había concretado en forma mayoritaria hasta marzo de 2020, donde por decreto Real 463/2020 del 14 de marzo, se declara la crisis sanitaria por COVID-19, adoptándose esta forma de trabajo en forma generalizada en las Administraciones Públicas, pero con carácter excepcional y temporal.

Este Real Decreto-ley modifica el texto de la Ley del Estatuto Básico del Empleado Público aprobado por Real Decreto Legislativo No.5/2015 de 30 de octubre, introduciendo un nuevo artículo - 47 bis - en el que se define el teletrabajo como aquella modalidad de prestación de servicios a distancia en la que el contenido competencial del puesto de trabajo puede desarrollarse - siempre que las necesidades del servicio lo permitan - fuera de las dependencias de la Administración, mediante el uso de tecnologías de la información y comunicación.

Se establece que el teletrabajo deberá contribuir a una mejor organización del trabajo a través de la identificación de objetivos y la evaluación de su cumplimiento, y ha de servir para la mejor consecución de los objetivos de la administración en su servicio a los intereses generales.

La modalidad de teletrabajo debe ser expresamente autorizada, a través de criterios objetivos y será compatible con la modalidad presencial que seguirá siendo la modalidad ordinaria de trabajo.

Los funcionarios que presten servicios de esta manera, tendrán los mismos deberes y derechos que el resto de los funcionarios públicos, debiendo la administración proporcionar y mantener los medios tecnológicos necesarios para desarrollar la actividad, siendo además de aplicación en lo pertinente la normativa de prevención de riesgos laborales.

En todo caso, tendrá carácter voluntario y reversible, salvo en supuestos excepcionales debidamente justificados

El desempeño concreto del teletrabajo se realizará en los términos de las normas de cada Administración Pública, siendo objeto de negociación colectiva en cada ámbito.

\subsubsection{Texto del Artículo 1 del Real Decreto-ley 29/2020, de 29 de setiembre de 2020 .}

Por su vigencia y actualidad, juzgamos de interés ilustrar debajo la norma recientemente aprobada en España y comentada precedentemente, que regula la modalidad de teletrabajo en las Administraciones Públicas en dicho país: 
"Artículo 1. Modificación del texto refundido de la Ley del Estatuto Básico del Empleado Público, aprobado por Real Decreto Legislativo 5/2015, de 30 de octubre.

Se introduce un nuevo artículo 47 bis en el texto refundido de la Ley del Estatuto Básico del Empleado Público, aprobado por Real Decreto Legislativo 5/2015, de 30 de octubre, que queda redactado en los siguientes términos:

«Artículo 47 bis. Teletrabajo.

1. Se considera teletrabajo aquella modalidad de prestación de servicios a distancia en la que el contenido competencial del puesto de trabajo puede desarrollarse, siempre que las necesidades del servicio lo permitan, fuera de las dependencias de la Administración, mediante el uso de tecnologías de la información y comunicación.

2. La prestación del servicio mediante teletrabajo habrá de ser expresamente autorizada y será compatible con la modalidad presencial. En todo caso, tendrá carácter voluntario y reversible salvo en supuestos excepcionales debidamente justificados. Se realizará en los términos de las normas que se dicten en desarrollo de este Estatuto, que serán objeto de negociación colectiva en el ámbito correspondiente y contemplarán criterios objetivos en el acceso a esta modalidad de prestación de servicio.

El teletrabajo deberá contribuir a una mejor organización del trabajo a través de la identificación de objetivos y la evaluación de su cumplimiento.

3. El personal que preste sus servicios mediante teletrabajo tendrá los mismos deberes y derechos, individuales y colectivos, recogidos en el presente Estatuto que el resto del personal que preste sus servicios en modalidad presencial, incluyendo la normativa de prevención de riesgos laborales que resulte aplicable, salvo aquellos que sean inherentes a la realización de la prestación del servicio de manera presencial.

4. La Administración proporcionará y mantendrá a las personas que trabajen en esta modalidad, los medios tecnológicos necesarios para su actividad.

5. El personal laboral al servicio de las Administraciones Públicas se regirá, en materia de teletrabajo, por lo previsto en el presente Estatuto y por sus normas de desarrollo.»". 


\subsection{Actualidad del Teletrabajo en el Gobierno Federal de los Estados Unidos.}

Veamos ahora cuál es la situación actual en el Gobierno Federal de Estados Unidos.

En el estudio a propósito del Decreto 420/007 llevado adelante por el Grupo de Investigación y Estudio en 2009, se daba cuenta de la génesis y desarrollo del fenómeno del teletrabajo en el gobierno federal de los Estados Unidos a partir del año 2000.

Indicábamos en aquella oportunidad que la base legislativa del teletrabajo en dicho ámbito la constituía la Ley Pública 106-346 del 23/10/2000 que encomendaba a la OPM (Oficina de Administración de Personal) delinear las políticas y lineamientos para aplicar dicha modalidad de trabajo.

Desde entonces, y hasta el presente, el teletrabajo ha continuado expandiéndose y se ha consolidado como forma de organizar el trabajo de los funcionarios públicos a nivel de las diversas Agencias del Gobierno Federal.

A nivel normativo, diez años después de la Ley Pública 106-346 antes mencionada, se aprobó la Ley Pública 111-292 del 9/12/2010, denominada “Ley de Mejora del Teletrabajo de 2010".

La Sección 2 de la Ley contiene una definición de "teletrabajo", con el siguiente alcance:

"El término "teletrabajo" refiere a un acuerdo de trabajo flexible bajo el cual un funcionario público desempeña tareas y responsabilidades inherentes a su cargo, y otras tareas autorizadas, desde un lugar de trabajo aprobado que es distinto al lugar desde el cual el funcionario público trabajaría de otro modo".

La norma contiene previsiones sobre "Elegibilidad para Teletrabajar" encomendando a las autoridades de cada agencia con funciones ejecutivas:

A) establecer una política conforme a la cual los funcionarios elegibles de la agencia puedan ser autorizados a teletrabajar;

B) determinar la elegibilidad de todos los funcionarios

de la agencia para participar en el teletrabajo, $y$

C) notificar a todos los funcionarios de la agencia sobre su elegibilidad para teletrabajar.

La regla general tiene, no obstante, limitaciones.

Así, por ejemplo, un funcionario no puede teletrabajar de acuerdo a las políticas contenidas en la Ley Pública si:

A) fue objeto de un procedimiento disciplinario por faltas no justificadas por más de 5 días en cualquier año calendario; o 
B) si el funcionario fue oficialmente sancionado por violaciones a las normas del Código de Conducta Ética de los Funcionarios de la Rama Ejecutiva por visualizar, descargar o intercambiar pornografía en una computadora del Gobierno Federal o mientras desempeñada deberes oficiales del Gobierno Federal.

En relación con la participación de los funcionarios en el programa de teletrabajo, la Ley manda que las políticas que establezcan las agencias federales deberán:

(i) asegurar que el teletrabajo no disminuya el desempeño del funcionario o las operaciones de la agencia;

(ii) requerir un acuerdo escrito entre las autoridades de la agencia y el funcionario autorizado a teletrabajar, que establezca el acuerdo de trabajo específico al que se haya arribado, como requisito obligatorio para que el funcionario pueda participar en el teletrabajo;

(iii) establecer que un funcionario no podrá ser autorizado a teletrabajar si su desempeño no cumple con los términos del acuerdo escrito entre las autoridades de la agencia y dicho funcionario; $y$

(iv) prever que excepto en situaciones de emergencia, la modalidad de teletrabajo no se aplicará a ningún funcionario de la agencia cuyos deberes oficiales requieran, en su trabajo diario, manejar material de seguridad que la agencia juzgue no es apropiado para la modalidad de teletrabajo, o realizar actividad en el lugar de trabajo que no pueda ser realizada o desempeñada remotamente o en otra ubicación.

Asimismo, la Ley establece que las agencias deberán incorporar el teletrabajo como parte de sus planes de continuidad de operaciones en caso de emergencia.

Es interesante advertir que estas disposiciones datan de hace 10 años, y que no obstante, adquieren en el actual contexto de pandemia de COVID-19 particular vigencia.

La Ley Pública prevé asimismo que cada agencia ejecutiva deberá poner en práctica un programa de entrenamiento en teletrabajo interactivo dirigido a todos los funcionarios que resulten elegibles para participar en el programa de teletrabajo de la agencia, y para todos sus supervisores.

La norma también deja en claro que todos los funcionarios que desempeñen sus tareas bajo la modalidad de teletrabajo estarán en igualdad de condiciones con los restantes funcionarios públicos en todo lo atinente a (i) evaluación de desempeño, (ii) oportunidades de capacitación, incentivos, promociones, reasignaciones, reducciones en escalafón, retención, o destitución, y (iii) exigencias de trabajo.

Para determinar los parámetros de lo que constituye "bajo rendimiento del funcionario", la agencia consultará los lineamientos de desempeño establecidos de la Oficina de Administración de Personal (OPM) del Gobierno Federal.

Cada agencia de la rama ejecutiva deberá designar un funcionario de la agencia como Oficial de Administración del Teletrabajo, cuyos deberes serán vigilar el desarrollo e im- 
plementación de los programas de teletrabajo de la agencia, asesorar al liderazgo de la agencia y a funcionarios y supervisores, y ser el punto principal de contacto en asuntos de teletrabajo entre la agencia y la OPM.

Finalmente, resultan de interés las normas en materia de seguridad de la información. La ciberseguridad era, y continúa siendo, una preocupación fundamental, y de especial atención en el desarrollo de la modalidad de teletrabajo en el gobierno federal.

La Ley Pública dispone que el gobierno federal deberá emitir lineamientos y políticas que, como mínimo, deberán prever los requisitos para:

A) el control del acceso a la información y a los sistemas de información de la agencia gubernamental;

B) proteger la información de la agencia, incluyendo la información de datos personales, y sus sistemas de información;

C) limitar la introducción de vulnerabilidades;

D) proteger los sistemas de información usados para teletrabajar, que no sean controlados por la agencia;

E) salvaguardar la infraestructura inalámbrica y de telecomunicaciones usada para teletrabajar; y

F) prevenir el uso inapropiado del tiempo y los recursos de la agencia que viole el Código de Ética de los Funcionarios de la Rama Ejecutiva.

Las estadísticas muestran un constante desarrollo y afianzamiento de la modalidad en el gobierno federal de los Estados Unidos a lo largo del tiempo.

Las cifras de una de las agencias pioneras en la adopción de esta modalidad de trabajo - la Oficina Estadounidense de Patentes y Marcas (USPTO) - son elocuentes. En el último informe publicado sobre el teletrabajo, la USPTO reporta que el $88 \%$ de la plantilla de funcionarios públicos de la Oficina trabaja remotamente de uno a cinco días de la semana, distribuyéndose en 47 estados de los Estados Unidos.

La agencia valora como extremadamente positiva la experiencia, con un alto impacto en la retención de talento en todo el país, mejora en la retención y la promoción de los funcionarios, aumento de la eficiencia, y mejora en las oportunidades de acceso a un trabajo flexible.

La USPTO subraya el aumento en la resiliencia de la agencia en materia de continuidad de operación ante eventos naturales (como por ejemplo cierres relacionados con eventos climáticos adversos), y un mayor compromiso de los funcionarios con los objetivos de la agencia. La USPTO tenía al 2018 más de 11.000 funcionarios desempeñándose en la modalidad de teletrabajo, de un total de 11.800 cargos elegibles para teletrabajar en toda la agencia, con un índice del $94 \%$ de cargos que resultan elegibles para dicha 
modalidad. Entre 2008 y 2018, casi se cuadruplicó el porcentaje de ahorro de la USPTO por la adopción del teletrabajo, y el número de funcionarios que trabajan remotamente aumentó de forma constante.

En materia de sostenibilidad y medio ambiente, el teletrabajo en la agencia implicó evitar manejar más de 70 millones de millas en un año, ahorrar millones en combustible, reducir emisiones en más de 37 mil toneladas/año.

El teletrabajo en el gobierno federal de los Estados Unidos aparece en la actualidad como un fenómeno probado y consolidado en la función pública, con información estadística cuantificable, y que cobró especial relevancia para la continuidad de la labor de la Administración ante el evento del COVID-19.

\section{Derecho Positivo en Uruguay.}

Ahora bien, en nuestro ordenamiento jurídico no hay una normativa específica para funcionarios públicos ni privados en Uruguay en materia de teletrabajo.

Actualmente se encuentra a consideración del Poder Legislativo un proyecto de ley para su regulación en la actividad privada.

Sin embargo, dada la realidad que se impuso como consecuencia de la pandemia por COVID-19, los funcionarios públicos en Uruguay pasaron a ejercer sus funciones - en los casos en que fue posible - desde sus domicilios.

Entre las normas que determinaron dicha situación encontramos las que se detallan a continuación:

1) El Decreto No 93/020, de 13 de marzo de 2020, que declaró Estado de Emergencia Nacional sanitaria como consecuencia de la pandemia originada por el virus COVID-19 (Coronavirus).

En este Decreto se disponen una serie de medidas relacionadas con dicha declaración.

Así, se suspenden los espectáculos públicos, se cierran centros turísticos termales públicos y privados, se habilita al Poder Ejecutivo a disponer el cierre de todos aquellos lugares de acceso público que se determinen, así como imponer todo otro tipo de medidas en materia de higiene sanitaria para evitar aglomeraciones en espacios públicos, se suspenden a nivel nacional eventos que impliquen aglomeración de personas.

Se encomienda asimismo a los Ministerios competentes la ejecución de todos los actos y operaciones materiales necesarias para el cumplimiento del decreto. Se exhorta a Entes Autónomos y Servicios Descentralizados a adoptar por decisiones internas las normas establecidas en el mismo.

En ese sentido, a través de estos instrumentos del Estado Social de Derecho - "actos de directiva" - el gobierno nacional busca acomodar toda la estrategia a seguir para enfrentar esta pandemia con criterios uniformes para todo el país. 
2) Posteriormente, el Decreto No. 94/020, de 16 de marzo de 2020, amplía las medidas dispuestas por la norma anterior, No. 93/020, con el fin de mitigar y prevenir las consecuencias de la propagación del virus COVID-19.

Entre otras disposiciones, su artículo 6 contiene una referencia expresa al "teletrabajo", que aplica tanto a la actividad privada como a la pública.

Establece dicho artículo:

"Exhórtase a todos los empleadores a instrumentar y promover, en todos los casos que sea posible, que los trabajadores realicen sus tareas en sus domicilios.

Esta situación deberá ser comunicada a la Inspección General de Trabajo a sus efectos. El empleador deberá suministrar los implementos necesarios para realizar la tarea encomendada".

3) Asimismo debe destacarse que la Ley N 19.879 , de 30/4/2020 efectúa la declaración de Feria Jurisdiccional Extraordinaria y suspensión de plazos procesales.

En esta norma también encontramos disposiciones referidas a teletrabajo.

Así, en su artículo 2 se establecen disposiciones especiales aplicables a la Feria Judicial Extraordinaria, donde se dispone que los jueces y los ministros de los Tribunales de Apelaciones, de la Suprema Corte de Justicia y del Tribunal de lo Contencioso Administrativo deberán realizar todos aquellos actos que sea posible cumplir y disponer, en guardias mínimas que aseguren el funcionamiento, a esos efectos de las oficinas judiciales, incluso en modalidad de teletrabajo.

En el mismo sentido se pronuncia con respecto a las oficinas de los distintos órganos jurisdiccionales, de acuerdo con lo que dispongan la Reglamentación de la Suprema Corte de Justicia y del Tribunal de lo Contencioso Administrativo en sus respectivos ámbitos de actuación.

Para los procedimientos administrativos se dispusieron medidas transitorias durante la Feria Jurisdiccional Extraordinaria y durante la Emergencia Sanitaria, estableciéndose el uso y difusión de vías electrónicas y telemáticas de relacionamiento remoto con los interesados.

\subsection{Antecedentes Normativos. Teletrabajo y Tecnología.}

Como antecedente normativo en materia de teletrabajo en Uruguay, resulta interesante destacar la creación de la AGESIC.

En efecto, en los artículos 73 y siguientes de la Ley No. 19.355 de 19 de diciembre de 2015 se crea la "Agencia para el Desarrollo del Gobierno de Gestión Electrónica y la Sociedad de la Información y del Conocimiento" (AGESIC), con el objetivo de promover y desarrollar estrategias de simplificación, priorización y puesta en línea de trámites en 
todas las entidades públicas, y en ese sentido se puede considerar como un avance en la instauración de herramientas tecnológicas que posibilitan el desarrollo del teletrabajo en la Administración Pública.

En esta norma se reconoce el derecho de las personas a relacionarse con las entidades públicas por medios electrónicos, para lo cual las entidades públicas deberán constituir domicilios electrónicos para el relacionamiento entre sí y con los administrados.

Entre otras disposiciones para simplificar trámites, se dispone que las entidades públicas deberán publicar en sus sitios web y en el Portal del Estado Uruguayo cada uno de los trámites que ofrecen, indicación de los requisitos que el interesado debe cumplir para su realización, el costo total que debe abonar, la duración del trámite y la dependencia donde debe realizarse el mismo.

Se establece que las entidades públicas deberán proveer medios electrónicos para la notificación de sus actuaciones a los interesados, proporcionando seguridad en cuanto a la efectiva realización de la diligencia y su fecha.

Se determina asimismo que las copias electrónicas que tengan indicación de haber sido realizadas por medios electrónicos de documentos electrónicos, emitidos por el propio interesado o por las entidades públicas, serán consideradas copias auténticas con la misma eficacia que el documento electrónico original, siempre que la información de firma electrónica permita comprobar su coincidencia.

La implementación de esta norma en las diferentes Instituciones públicas ha posibilitado que el funcionario público pueda desarrollar su tarea desde cualquier lugar, en la medida que esté conectado a los servidores informáticos de la entidad pública para la cual se desempeña.

3.2 Intersección entre teletrabajo en la función pública y otras normas. Protección de Datos Personales. Ciberseguridad.

El fenómeno del teletrabajo en la función pública da lugar al encuentro entre el Derecho y la Tecnología y a la intersección entre esta modalidad y otras normas.

Dentro de ellas, reviste particular interés la incidencia de normativa de protección de datos personales en este contexto.

El derecho a la privacidad tiene raigambre constitucional en Uruguay, y deriva de la Constitución de la República. A pesar de no estar nombrado expresamente en la misma, el derecho a la protección de la intimidad y de los datos personales, es considerado un Derecho Humano, incluido por la vía del artículo 72 de la Constitución, que establece:

"La enumeración de derechos, deberes y garantías hecha por la Constitución, no excluye los otros que son inherentes a la personalidad humana o se derivan de la forma republicana de gobierno". 
El marco legal incluye también las Convenciones Internacionales de las que Uruguay forma parte, entre otras, la Convención Americana sobre Derechos Humanos, también conocida como Pacto de San José de Costa Rica, aprobada por Uruguay por Ley No. 15.737 del 8 de marzo de 1985. El artículo 11 de la Convención consagra la "Protección de la Honra y de la Dignidad" y en particular, dispone que "Nadie puede ser objeto de injerencias arbitrarias o abusivas en su vida privada, en la de su familia, en su domicilio o en su correspondencia, ni de ataques ilegales a su honra o reputación", gozando toda persona del derecho a la protección de la ley contra esas injerencias o esos ataques.

En Uruguay, la primera norma específica relativa a la Protección de Datos Personales fue la Ley No. 17.838 del 24 de setiembre de 2004, que reguló la protección de los datos personales utilizados en informes comerciales, y también la acción de Habeas Data.

Fue reemplazada por la Ley No. 18.331 del 11 de agosto de 2008 sobre Protección de Datos Personales y la Acción de Habeas Data), referida de aquí en adelante como "LPDP".

Si bien, como se mencionó arriba, la Constitución de Uruguay no menciona expresamente el derecho a la protección de los datos de carácter personal, su protección ingresa en la Constitución de forma implícita, por su carácter de Derecho Humano incorporado por el Artículo 72 de la Carta, al cual se refiere expresamente la LPDP en su artículo 1.

Entre otras normas que completan el marco legal en Uruguay, resultan de interés a la temática que analizamos en este trabajo, las relativas a seguridad de la información, la Ley No. 18.362 del 6 de octubre de 2008 que creó el "Centro Nacional de Respuesta a Incidentes de Seguridad Informática" (CERTuy), y Ley No. 19.670, de 15 de octubre de 2018, de aprobación de Rendición de Cuentas y Balance de Ejecución Presupuestal. Ejercicio 2017. Esta última establece condiciones para la aplicación extraterritorial de la ley uruguaya sobre protección de datos. Impone obligaciones y condiciones del informe de vulneraciones de seguridad y pérdida de datos. Establece la obligación de que ciertas entidades cuenten con un Delegado de Protección de Datos.

El ámbito subjetivo de aplicación de la normativa en materia de privacidad y protección de datos personales, abarca tanto a personas privadas, como públicas.

En este marco, y en el contexto de la pandemia de COVID-19, el 10 de agosto de 2020 la Unidad Reguladora y de Control de Datos Personales de Uruguay (URCDP), puso a disposición una serie de recomendaciones para la "protección de datos personales en tiempos de teletrabajo". Estas recomendaciones están relacionadas con la protección de datos personales en la implementación de estrategias de teletrabajo en las organizaciones públicas y privadas.

La URCDP parte de constatar que la emergencia nacional sanitaria, declarada por el ya mencionado Decreto $N^{\circ}$ 93/020 de 13 de marzo de 2020, dictado a consecuencia de la pandemia de COVID-19, y que ello "ha generado, y en muchos casos potenciado, el empleo de instrumentos de teletrabajo" ${ }^{10}$.

10 URCDP, “La protección de datos personales en tiempos de teletrabajo”, en https://www.gub.uy/unidad-regulado- 
La Unidad apunta que "se han vuelto comunes las herramientas que permiten reuniones a distancia, su grabación y almacenamiento, el intercambio de archivos, la utilización de la nube, entre otros; lo que se traduce además en un incremento exponencial en el tratamiento de información personal a través de Internet".

Las recomendaciones recogen buenas prácticas para el el tratamiento de datos personales en el marco del teletrabajo, que tengan en cuenta y aseguren el cumplimiento de las disposiciones de la Ley de Protección de Datos No. 18.831 y protejan adecuadamente los derechos de los titulares de los datos.

Lo anterior se complementa con las recomendaciones de la URCDP de carácter técnico - para organizaciones tanto públicas como privadas - para realizar teletrabajo, que incluyen pautas sobre el uso seguro de equipos y medios informáticos, cuidado de la información, canales de comunicación, continuidad de las operaciones y Planes de Continuidad, atención de los usuarios, ciberseguridad, y adopción de programas de videoconferencias ${ }^{11}$.

\section{Reflexiones Finales. Virtudes, defectos y prospectiva.}

De esta breve reseña de la regulación del teletrabajo en el Derecho Comparado y en nuestro Derecho Positivo, si algo podemos concluir es que esta modalidad de trabajo no ya tan nueva - se ha visto afianzada y potenciada como consecuencia de la situación de pandemia - y vino para quedarse.

Sin lugar a dudas, y como fluye del rápido relevamiento realizado, en Derecho Comparado existe una mayor regulación en relación a su forma de prestación, que la incipiente que surge en nuestro ordenamiento.

En la medida en que las realidades sean similares, podremos beneficiarnos con la experiencia de otros países para adaptar y de ser el caso, adoptar, algunas de las previsiones normativas aprobadas en otras jurisdicciones.

No puede soslayarse que esta modalidad de prestación de la función pública, tiene sus beneficios y sus desventajas, lo que no hace más que confirmar esa constante tensión entre autoridad y libertad a que nos referíamos inicialmente, inherente al Derecho Administrativo.

Entre sus beneficios, y sin ánimo de agotar la lista, podemos mencionar una mayor protección del medio ambiente, en tanto se disminuye la circulación de vehículos y demás medios de transporte; brinda mayor flexibilidad en la realización de las tareas; favorece además, sin duda alguna el trabajo para personas con capacidades diferentes o incluso aquellas personas que por motivos familiares deben permanecer en sus domicilios, evitando ausentismo de los funcionarios por estos motivos. Asimismo esta modalidad fomenta la realización del trabajo a través de la fijación de metas y objetivos y no

ra-control-datos-personales/comunicacion/noticias/proteccion-datos-personales-tiempos-teletrabajo.

11 URCDP, "Recomendaciones técnicas para realizar teletrabajo", en https://www.gub.uy/agencia-gobierno-electronico-sociedad-informacion-conocimiento/comunicacion/publicaciones/recomendaciones-tecnicas-para-realizar-teletrabajo. 
en función de un horario de cumplimiento, lo que en definitiva redundaría en una mejor eficiencia en los servicios públicos.

En el otro extremo, como elemento negativo, la no concurrencia a los lugares de trabajo puede determinar que las asociaciones gremiales o sindicales pierdan fuerza en sus reclamos ya que varias de las medidas que adoptan en sus reivindicaciones suponen necesariamente la presencia del trabajador en su lugar de trabajo.

Por otra parte, no puede soslayarse que esta forma de prestación puede favorecer el aislamiento, lo que puede redundar en forma perjudicial para el desarrollo en sociedad de las personas.

Pero más allá de considerar esos beneficios y desventajas, virtudes y debilidades, lo que debe tenerse en cuenta es, como señala Ivanega que "...el trabajo es condición propia del hombre, constituye una dimensión fundamental de su existencia sobre la tierra; pero a la vez, por conformar una actividad humana, no se la puede separar de quien la cumple. Así es parte de su dignidad" ${ }^{12}$.

El respeto, pues, al trabajo, a la hora de regular su prestación - cualquiera sea su modalidad - es un pilar que debe tener en cuenta el creador del derecho, y en especial en relación a la función pública, ya que no puede perderse de vista que el empleador es una Administración Pública.

De manera inmejorable, el Papa Juan Pablo II, en su Encíclica Laborem Exercens, se refirió al trabajo en estos términos:

"El trabajo es una de las características que distinguen al hombre del resto de las criaturas, cuya actividad relacionada con el mantenimiento de la vida, no puede llamarse trabajo; solamente el hombre es capaz de trabajar, solamente él puede llevarlo a cabo, llenando a la vez con el trabajo su existencia sobre la tierra. De este modo el trabajo lleva en sí un signo particular del hombre y de la humanidad, el signo de la persona activa en medio de una comunidad de personas; este signo determina su característica interior y constituye en cierto sentido su misma naturaleza" ${ }^{13}$.

\section{BIBLIOGRAFÍA}

Grupo de Investigación y Estudio de la Facultad de Derecho de la Universidad de Montevideo (2009). Reflexiones a propósito del Decreto 420/007 y las formas modernas de prestación de la función pública, Revista de Derecho de la Universidad de Montevideo, Año VIII, No. 16.

Rotondo, Felipe (2009). Manual de Derecho Administrativo, $7^{\text {a }}$. edición, Ediciones del Foro, pág. 24 y ss.

12 Ivanega, Miriam "Las relaciones de empleo público frente a la globalización del Derecho Administrativo" en Estudios Jurídicos en Homenaje al Profesor Juan Pablo Cajarville Peluffo, FCU, 1ª Edición, Año 2011, pág.167 y ss.

13 Citado por Ivanega, Miriam, Op. Cit., pág. 168. 
Brito, Mariano (2004). Derecho Administrativo, Su Permanencia-Contemporaneidad-Prospectiva, Ed. Universidad de Montevideo, pág. 9 y ss.

Federico, Mario E. Gobernabilidad democrática y Estado de Derecho frente a las emergencias económicas y sociales, citado por Brito, Mariano (2004), Derecho Administrativo, Su Permanencia-Contemporaneidad-Prospectiva, Ed. Universidad de Montevideo, pág. 15.

Meilán Gil, José Luis, citado por Rotondo Felipe (2009), Manual de Derecho Administrativo, $7^{\mathrm{a}}$. edición, Ediciones del Foro, pág. 24 y ss.

Agencia Estatal Boletín Oficial del Estado (2020). En https://www.boe.es/diario_ boe/txt.php?id=BOE-A-2020-11415.

USPTO (United States Patent and Trademark Office) (2018). Telework Annual Report. En: https://www.uspto.gov/sites/default/files/documents/Telework_Annual_Report_2018\%20508\%20Compliant.pdf

IMPO - Centro de información Oficial (2020). Sección Normativa y Avisos Legales del Uruguay. En https://www.impo.com.uy/cgi-bin/bases/consultaBasesBS.cgi?tipoServicio $=3$.

URCDP (2020). La protección de datos personales en tiempos de teletrabajo, en https:// www.gub.uy/unidad-reguladora-control-datos-personales/comunicacion/noticias / proteccion-datos-personales-tiempos-teletrabajo.

URCDP (2020). Recomendaciones técnicas para realizar teletrabajo, en https:/ /www.gub. uy/agencia-gobierno-electronico-sociedad-informacion-conocimiento/comunicacion/ publicaciones/recomendaciones-tecnicas-para-realizar-teletrabajo.

Ivanega, Miriam (2011). Las relaciones de empleo público frente a la globalización del Derecho Administrativo, en Estudios Jurídicos en Homenaje al Profesor Juan Pablo Cajarville Peluffo, FCU, 1ª . Edición, pág.167 y ss.

Papa Juan Pablo II (1981). Encíclica Laborem Exercens, citado por Ivanega, Miriam (2011), Las relaciones de empleo público frente a la globalización del Derecho Administrativo, en Estudios Jurídicos en Homenaje al Profesor Juan Pablo Cajarville Peluffo, FCU, 1ª Edición, pág. 168. 